\title{
Characteristics of surgical prosthetic heart valves and problems around labeling: A document from the European Association for Cardio-Thoracic Surgery (EACTS)—The Society of Thoracic Surgeons (STS)_American Association for Thoracic Surgery (AATS) Valve Labelling Task Force
}

\author{
Andras P. Durko, ${ }^{\text {a,b }}$ Stuart J. Head, ${ }^{\text {a }}$ Philippe Pibarot,${ }^{\mathrm{c}}$ Pavan Atluri, ${ }^{\mathrm{d}}$ Vinayak Bapat, ${ }^{\mathrm{e}}$ Duke E. Cameron, \\ Filip P. A. Casselman, ${ }^{\mathrm{g}}$ Edward P. Chen, ${ }^{\mathrm{h}}$ Gry Dahle, ${ }^{\mathrm{i}}$ Tjark Ebels, ${ }^{\mathrm{j}}$ John A. Elefteriades, ${ }^{\mathrm{k}}$ \\ Patrizio Lancellotti, ${ }^{1}$ Richard L. Prager, ${ }^{\mathrm{m}}$ Raphael Rosenhek, ${ }^{\mathrm{n}}$ Alan Speir, ${ }^{\mathrm{o}}$ Marco Stijnen, ${ }^{\mathrm{p}}$ \\ Giordano Tasca, ${ }^{\mathrm{q}}$ Ajit Yoganathan, ${ }^{\mathrm{r}}$ Thomas Walther, ${ }^{\mathrm{s}}$ and Ruggero De Paulis (Task Force Chairman), \\ EACTS-STS-AATS Valve Labelling Task Force
}

\begin{abstract}
Intraoperative surgical prosthetic heart valve (SHV) choice is a key determinant of successful surgery and positive postoperative outcomes. Currently, many controversies exist around the sizing and labeling of SHVs rendering the comparison of different valves difficult. To explore solutions, an expert Valve Labelling Task Force was jointly initiated by the European Association for Cardio-Thoracic Surgery (EACTS), The Society of Thoracic Surgeons (STS) and the American Association for Thoracic Surgery (AATS). The EACTS-STSAATS Valve Labelling Task Force, comprising cardiac surgeons, cardiologists, engineers, regulators and representatives from the International Organization for Standardization (ISO), and major valve manufacturers, held its first in-person meeting in February 2018 in Paris, France. This article was derived from the meeting's discussions. The Task Force identified the following areas for improvement and clarification: reporting of physical dimensions and characteristics of SHVs determining and labeling of SHV size, in vivo and in vitro testing, and reporting of SHV hemodynamic performance and thrombogenicity. Furthermore, a thorough understanding of the regulatory background and the role of the applicable ISO standards, together with close cooperation between all stakeholders (including regulatory and standard- setting bodies), is necessary to improve the current situation. Cardiac surgeons should be provided with appropriate information to allow for optimal SHV choice. This first article from the EACTS-STS-AATS Valve Labelling Task Force summarizes the background of SHV sizing and labeling and identifies the most important elements where further standardization is necessary. (J Thorac Cardiovasc Surg 2019;158:1041-54)
\end{abstract}

\footnotetext{
From the a Department of Cardiothoracic Surgery, Erasmus University Medical Center, Rotterdam, The Netherlands; ${ }^{\mathrm{b}}$ Department of Cardiac Surgery, Medical and Health Science Centre, University of Debrecen, Debrecen, Hungary; ' ${ }^{\text {Québec }}$ Heart and Lung Institute, Laval University, Quebec City, Quebec, Canada; ${ }^{\mathrm{d}}$ Division of Cardiovascular Surgery, Department of Surgery, University of Pennsylvania, Philadelphia, Pa; ${ }^{\mathrm{e}}$ Department of Cardiovascular Surgery, New York-Presbyterian/Columbia University Medical Center, New York, NY; ${ }^{\mathrm{f}}$ Division of Cardiac Surgery, Department of Surgery, Massachusetts General Hospital, Boston, Mass; ${ }^{\mathrm{g}}$ Department of Cardiovascular and Thoracic Surgery, OLV Clinic, Aalst, Belgium; hivision of Cardiothoracic Surgery, Department of Surgery, Emory University School of Medicine, Atlanta, Ga; ${ }^{\mathrm{i}}$ Department of Cardiothoracic and Vascular Surgery, Rikshospitalet, Oslo University Hospital, Oslo, Norway; ${ }^{\mathrm{j}}$ Department of Cardiothoracic Surgery, Amsterdam University Medical Center, Amsterdam, The Netherlands; ${ }^{k}$ Department of Cardiothoracic Surgery, Yale University School of Medicine, New Haven, Conn; ${ }^{1}$ Department of Cardiology, GIGA Cardiovascular Sciences, University of Liège Hospital, Liège, Belgium; ${ }^{\mathrm{m}}$ Department of Cardiac Surgery, University of Michigan Hospital, Ann Arbor, Mich; ${ }^{\mathrm{n}}$ Department of Cardiology, Medical University of Vienna, Vienna, Austria; ${ }^{\circ}$ Department of Cardiac Surgery, Inova Heart and Vascular Institute, Falls Church, Va; ${ }^{\mathrm{P}}$ LifeTec Group, Eindhoven, The Netherlands; ${ }^{\mathrm{q}}$ Cardiovascular Department, Operative Unit of Cardiac Surgery, Hospital A. Manzoni, Lecco, Italy; ${ }^{\text {r} W a l l a c e ~}$ H. Coulter Department of Biomedical Engineering, Georgia Institute of Technology/Emory School of Medicine, Atlanta, Ga; ${ }^{\mathrm{s}}$ Department of Thoracic and Cardiovascular Surgery, University Hospital Frankfurt, Johann Wolfgang Goethe University Frankfurt, Frankfurt, Germany; and 'Department of Cardiac Surgery, European Hospital, Rome, Italy.
}

This article has been co-published with permission in the European Journal of Cardio-Thoracic Surgery, The Annals of Thoracic Surgery, and The Journal of Thoracic and Cardiovascular Surgery.

The articles are identical except for minor stylistic and spelling differences in keeping with each journal's style. Either citation can be used when citing this article.

This work was supported by the European Association for Cardio-Thoracic Surgery (EACTS). We acknowledge the financial support from the Netherlands Cardio Vascular Research Initiative: the Dutch Heart Foundation, Dutch Federation of University Medical Centres, the Netherlands Organisation for Health Research and Development and the Royal Netherlands Academy of Sciences.

Cite this article as: Durko AP, Head SJ, Pibarot P, Atluri P, Bapat V, Cameron DE, et al. Characteristics of surgical prosthetic heart valves and problems around labelling: a document from the European Association for Cardio-Thoracic Surgery (EACTS) - The Society of Thoracic Surgeons (STS)-American Association for Thoracic Surgery (AATS) Valve Labelling Task Force. J Thorac Cardiovasc Surg. 2019;158:1041-54.

Received for publication Nov 2, 2018; revisions received Jan 8, 2019; accepted for publication Jan 17, 2019; available ahead of print May 10, 2019.

Reprint request: Ruggero De Paulis, Department of Cardiac Surgery, European Hospital, Via Portuense 700, 00149 Rome, Italy (E-mail: rdepaulis58@ gmail.com). $0022-5223 / \$ 36.00$

(C) 2019 by The Society of Thoracic Surgeons, The American Association for Thoracic Surgery, and the European Association for Cardio-Thoracic Surgery https://doi.org/10.1016/j.jtcvs.2019.04.001 
See Commentary on page 1055.

Intraoperative prosthetic valve selection is a key determinant of surgical success; using the most appropriate surgical prosthetic heart valve (SHV) minimizes the risks of surgery, maximizes hemodynamic performance, and optimizes long-term outcomes. ${ }^{1}$ The final choice of an SHV, including appropriate size, is typically made in the operating theatre. To facilitate an evidence-based SHV choice, sufficient appropriate information on SHV characteristics is required. Background information from medical literature is not available in the intraoperative setting, so SHV package labels and instructions for use (IFU) booklets are the primary sources of information for the surgeon in the operating theatre.

In both the European Union (EU) and the USA, the quality and quantity of information provided with an SHV are regulated. The International Organization for Standardization (ISO) plays an important role in this process by providing a framework for regulatory bodies. ${ }^{2}$ Although the ISO 5840 standard (Cardiovascular Implants-Cardiac Valve Prostheses) provides general conditions for testing SHVs for human implantation and defines operational and labeling requirements, the current labeling situation is not optimal. Simple definitions such as "labeled valve size" are often unclear, and inconsistencies and controversies exist around the sizing and labeling of SHVs in relation to hemodynamic performance. $^{3}$

To resolve these issues, the European Association for Cardio-Thoracic Surgery (EACTS), The Society of Thoracic Surgeons (STS) and the American Association for Thoracic Surgery (AATS) set up the EACTS-STS-AATS Valve Labelling Task Force, involving representatives of the 3 surgical societies, cardiologists, engineers, regulatory professionals and representatives from ISO and major valve-manufacturing companies. The discussions during the first in-person meeting of the Task Force (held in February 2018, Paris, France) provided the core content of this article.

This first article of the EACTS-STS-AATS Valve Labelling Task Force is intended to provide an overview of important characteristics of SHVs relating to sizing and labeling, reviews current practices in these areas, and identifies where improvements are necessary. This article will be followed by an expert consensus document containing recommendations on SHV sizing and labeling.

\section{REGULATORY ASPECTS AND USE OF STANDARDS IN PROSTHETIC HEART VALVE LABELING}

In the EU and the USA, medical devices must demonstrate conformity to the local legislations before they can be introduced to the market. Assessment of conformity is defined as the evaluation of whether a certain device is safe and effective according to the applicable regulations. This includes the assessment of the device labeling information, including the IFU and package labels. The ISO standards play an important role in defining these devicespecific requirements.

\section{International Organization for Standardization and the Prosthetic Heart Valve Standards}

Technical standards are formal documents, defining uniform engineering criteria for technical systems. The ISO is an independent, nongovernmental organization consisting of national standards bodies. ${ }^{4}$ Manufacturers globally use ISO standards during product development and production. In addition, ISO standards are widely utilized by regulatory bodies as a conformity assessment tool for market approval. The ISO standards are periodically revised and updated in line with new innovations.

"ISO 5840" is a family of standards developed by a group of professionals from engineering and medical backgrounds, including representatives of the medical device industry, regulators, and clinicians. The current 2015 version (ISO 5840:2015, Cardiovascular Implants-Cardiac Valve Prostheses) consists of 3 parts: "part 1: general requirements, part 2: surgically implanted heart valve substitutes, and part 3: heart valve substitutes implanted by transcatheter techniques." "ISO 5840:2015" provides recommendations and requirements for preclinical and clinical evaluations of $\mathrm{SHVs}^{2}$ and it defines valve-related objective performance criteria according to linearized event rates of key safety end points (thromboembolism, valve thrombosis, hemorrhage, paravalvular leakage, and endocarditis). ${ }^{2,5,6}$ Furthermore, ISO provides guidance on labeling by describing the information that should be available on the product labels and in the IFU, including detailed information on intended use, indications/contraindications and warnings, and physical and performance characteristics. ${ }^{2}$

\section{Standards and Prosthetic Heart Valve Approval in the European Union}

In the EU, the regulatory framework provided by the European Commission sets the general requirements for the whole range of medical devices. ${ }^{7,8}$ More specific requirements are defined within "Common Specifications" or in "Harmonized Standards." The European Committee for Standardization (CEN) cooperates with the ISO, and existing ISO standards can be adopted as "Harmonized Standards" endorsed by the European Commission. ${ }^{9}$ Furthermore, technical standards are used as a tool to define the generally acknowledged "state of the art" in a certain field. To define "state of the art," other documents such as consensus documents by professional societies are also taken into account during conformity assessment. ${ }^{8}$ 
In the EU, conformity assessment of medical devices is performed by Notified Bodies. These are independent, third-party organizations appointed by Member States. Notified Bodies can grant the CE (European Conformity) mark, which allows marketing a product within the European Economic Area.

\section{Standards and Prosthetic Heart Valve Approval in the USA}

In the USA, the medical device market is centrally regulated by the Food and Drug Administration (FDA) through review and approval of applications for new devices. ${ }^{10}$ During the process of approving new SHVs, the use of "Consensus Standards" by the FDA is voluntary. ${ }^{11}$ The ISO 5840 standards are recognized by the FDA and could serve as a guidance for manufacturers when submitting their applications for approval to the FDA. ${ }^{12}$

\section{DESIGN AND CHARACTERISTICS OF SURGICAL PROSTHETIC HEART VALVES \\ Design and Materials}

The design and component materials of an SHV should: cause minimal harm to endothelial tissue and blood cells; pose minimal chances for platelet and thrombus deposition; be resistant to structural wear and tear, mechanical failure, and degradation; be biochemically inert in a physiological milieu; and be suitable for sterilization. ${ }^{13}$ Mechanical valve leaflets and their supporting frames are composed mostly of pyrolytic carbon. Bioprosthetic valves, however, have more variation in their component materials: both native valves from animals and valves manufactured from animal pericardium are used (Table 1). Preparation techniques used for biological tissues aim to reduce immunogenicity, ${ }^{14}$ crosslink collagen, and prevent calcification to delay valve degeneration. ${ }^{15}$ Polymeric heart valves might offer a relatively inexpensive alternative to biological tissues, but their safety and effectiveness in the clinical setting are yet to be proved. $^{16,17}$ Differences in long-term outcomes with various prostheses have been identified, which may relate to specific design features. ${ }^{18,19}$

Materials used for the supporting frames of bioprosthetic valves vary in composition (Table 1), which is potentially relevant for subsequent valve-in-valve transcatheter procedures, when bioprosthetic valve frame fracture could enable insertion of a larger transcatheter prosthesis. ${ }^{20}$ Importantly, some bioprosthetic SHVs are equipped with an expandable band, which is intended to facilitate controlled expansion of the valve support structure when subjected to radial force. Many SHVs are equipped with radiopaque markers or have an intrinsically radiopaque support structure. This is useful when a valve-in-valve procedure is planned, as it aids in positioning of the transcatheter valve and provides information about the proximity of the SHV strut to the coronary ostia. Currently, there is a considerable variety in radiopaque marking of bioprosthetic SHVs. ${ }^{21}$

The "ISO 5840:2015" standard contains recommendations on reporting the magnetic resonance imaging (MRI) safety designation of the prosthesis in the accompanying IFU. However, it does not require detailed reporting of the materials used for SHV manufacturing.

\section{Physical Dimensions}

Physical dimensions of SHVs are closely related to their performance, safety, and ease of use, and can influence the choice of prosthesis and the implantation technique. Dimensions are defined in "ISO 5840:2015" and should be provided in the IFU. ${ }^{2}$ However, reporting of these measurements in terms of dimensional definitions is not consistent, and the relationship between SHV physical dimensions and the "labeled valve size" is unclear, creating confusion in the surgical community. ${ }^{3}$

Axial dimensions. The fundamental axial dimensions of an SHV are the overall "profile height" and "outflow tract profile height," the latter being the maximum distance that the heart valve substitute extends axially into the outflow tract, measured from the valve structure's intended annular attachment, according to "ISO 5840:2015" (Figures 1 and 2). ${ }^{2}$

Horizontal dimensions. The ISO-defined horizontal dimensions of an SHV are the "internal orifice diameter" and the "external sewing ring diameter" (Figures 1 and 2). According to "ISO 5840:2015," "internal orifice diameter" is "the minimum diameter within a surgical heart valve substitute through which blood flows,"2 making it one of the most relevant physical dimensions characterizing SHV performance.

A widely used parameter when selecting a transcatheter prosthesis during a valve-in-valve procedure is the "true internal diameter" (true ID) of the surgical bioprosthesis. This "true ID" is measured by passing a Hegar dilator

TABLE 1. Component materials in stented surgical prosthetic heart valves

\begin{tabular}{lll}
\hline & \multicolumn{1}{c}{ Stented bioprostheses } & Mechanoprostheses \\
\hline Leaflets & Native porcine valve and bovine pericardium & Pyrolytic carbon \\
Supporting frame/stent & Titanium, Elgiloy, ${ }^{*}$ and Delrin $\dagger$ & Pyrolytic carbon and titanium \\
Sewing ring & Silicone rubber and Dacron $\downarrow$ & Dacron and Teflon $\S$ \\
\hline
\end{tabular}

*Cobalt-chromium-nickel-molybdenum alloy. †Acetal homopolymer. ఫ̦Polyethylene terephthalate. §Polytetrafluoroethylene. 

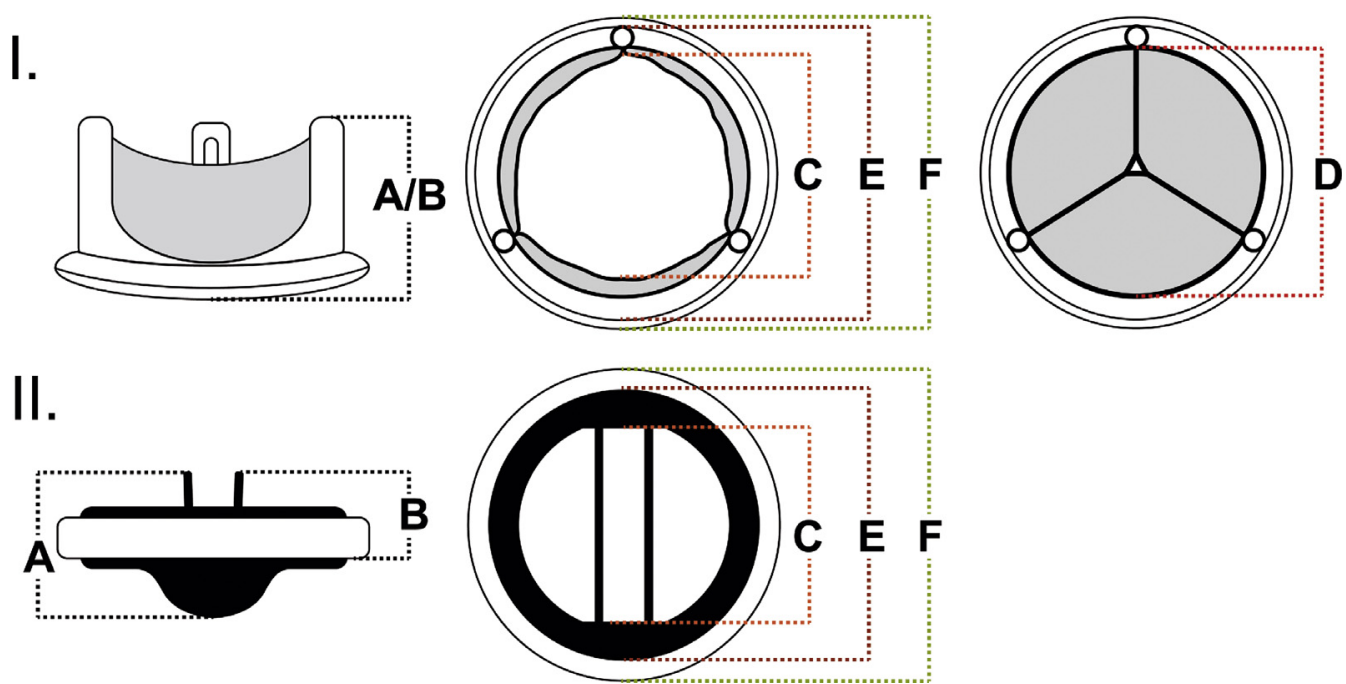

FIGURE 1. Physical dimensions of surgical prosthetic heart valves, aortic position. (I) Typical tissue valve. (II) Typical bileaflet mechanoprosthesis. (A) Overall profile height; $(B)$ outflow tract profile height; $(C)$ internal orifice diameter; $(D)$ internal diameter/internal stent diameter; $(E)$ external stent/housing diameter; $(F)$ external sewing ring diameter.

through the bioprosthetic orifice and therefore closely corresponds to the ISO-defined "internal orifice diameter." 22 Of note, manufacturers often report "internal diameter (ID)" or "stent internal diameter (stent ID)," which is the ID of the stent (label F in Figures 1 and 2). Importantly, this "stent ID" does not account for the space occupied by the prosthetic leaflets in the orifice of a bioprosthetic valve (eg, the difference between labels $\mathrm{C}$ and $\mathrm{D}$ in Figures 1 and 2).

Labeled valve size. Importantly, rather than being a strictly valve-related physical parameter, labeled "valve size," according to "ISO 5840:2015," is an indicator of the "tissue annulus diameter of the patient into whom the surgical heart valve substitute is intended to be implanted."2 In other words, the labeled "valve size" is not based on any single valve-related physical dimension, according to ISO definitions. This is a source of profound confusion in the cardiac surgical community. ${ }^{23}$

Another problem is the common erroneous perception of a direct relationship between labeled valve size and hemodynamic performance. ${ }^{24}$

\section{Sewing Ring}

The sewing ring enables an SHV to be secured to the patient's tissue annulus. Sewing rings must be biocompatible and capable of sustaining expected in vivo loading.

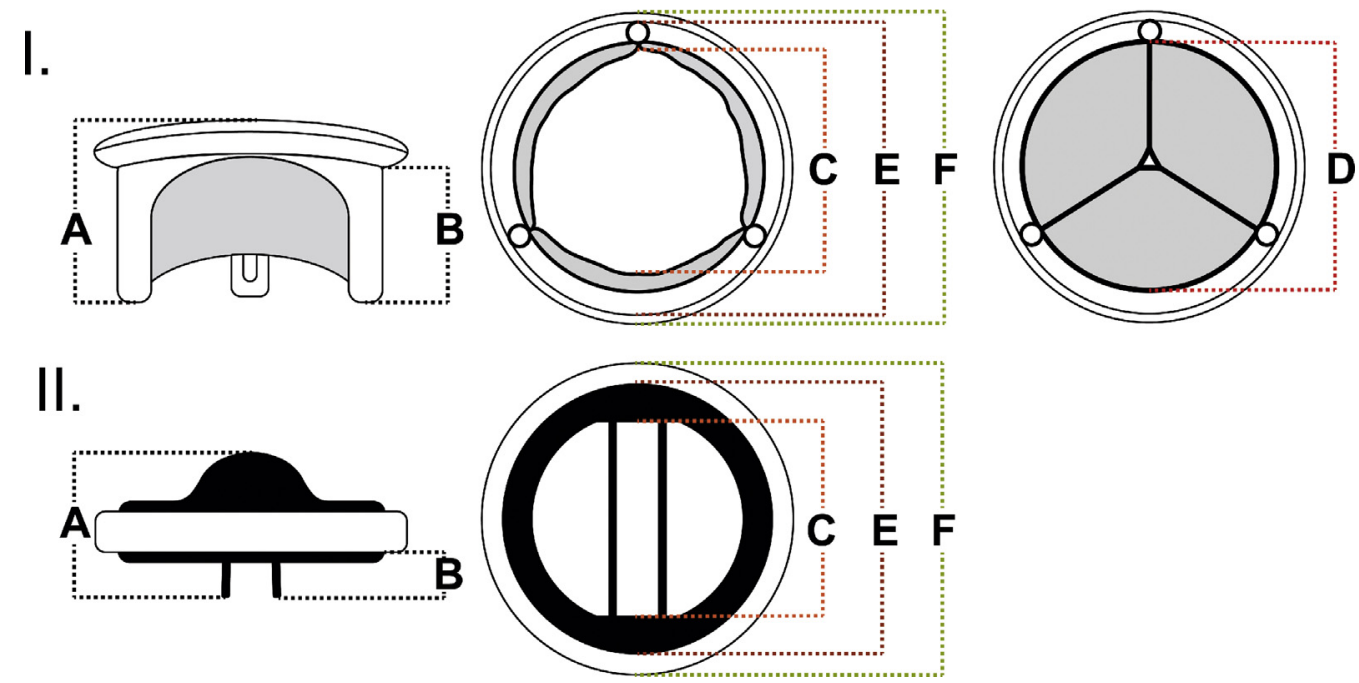

FIGURE 2. Physical dimensions of surgical prosthetic heart valves, mitral position. (I) Typical tissue valve. (II) Typical bileaflet mechanoprosthesis. (A) Overall profile height; $(B)$ Outflow tract profile height; $(C)$ Internal orifice diameter; $(D)$ Internal diameter/internal stent diameter; $(E)$ external stent/housing diameter; $(F)$ external sewing ring diameter. 


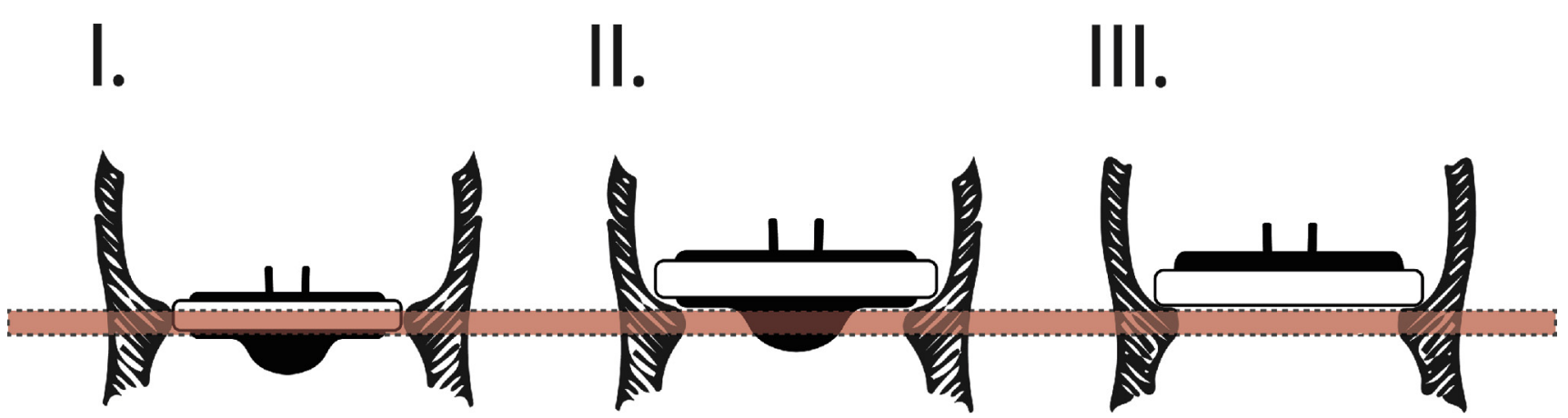

FIGURE 3. Possible positions of a prosthetic heart valve in relation to the aortic annulus (red line). (I) The valve is positioned in the annulus- "intraannular." (II) The valve "partially" extends into the level of the annulus-unclear situation. (III) The valve is "wholly" above the annulus- "supraannular."

Intra- and supra-annular positioning. The sewing ring determines the position of the SHV in relation to the patient's tissue annulus. According to "ISO 5840:2015," a supra-annular sewing ring is a "sewing ring designed to secure the valve 'wholly above' the patient's tissue annulus," while an intra-annular sewing ring is a "sewing ring designed to secure the surgical heart valve "wholly or mostly within' the patient's tissue annulus." "2 Although there is some controversy surrounding exact definitions of intra-annular and supra-annular positions of the valve (Figure 3), this information is sometimes displayed on product labels or used in marketing materials. Despite the design of an SHV, surgeons can implant most valves in either intraor supra-annular positions using specific suturing techniques.

Sewing ring shape and suture markers. Sewing rings can be designed as completely flat structures or can have a curvilinear form that aims to provide alignment with the patient's nonplanar anatomical annulus. Suture markers on the sewing ring are intended to facilitate implantation and correct orientation of the SHV. Currently, there is a considerable variety in the number and position of suture markers. Implantation aids. Several implantation aids are provided with an SHV, including handles, rotators, or systems to prevent inadvertent suture looping and/or facilitating knottying. According to "ISO 5840:2015," the use of these implantation aids should be described in the IFU.

\section{Intraoperative Sizing}

The goal of intraoperative sizing is to determine the labeled size of the SHV that can be safely implanted into the patient. This information, together with easy access to information about the relevant properties (eg, hemodynamic performance, durability, thrombogenicity, etc) of the particular SHV that would fit, makes optimal intraoperative valve choice possible.

Sizers. Manufacturers provide a set of valve-related sizers for each SHV model. Sizers are numbered according to the labeled sizes of the corresponding SHVs. Typically, sizers have 2 ends: a cylindrical end (barrel) to measure the annulus and guide SHV selection based on the labeled valve size, and a replica mimicking the configuration of the prosthesis (Figure 4). Sizing with a replica after suture placement is particularly useful because both the patient's anatomy and the surgeon's suturing technique influence the SHV's final position and affect ultimate sizing. ${ }^{25,26}$

Sizers and the labeled valve size. Given that the numbering of sizers follows the labeled valve size, the sizer barrel should determine the diameter of the patient's tissue annulus. Indeed, size measured using the sizer barrel is not intended to provide direct information regarding the physical dimensions of the corresponding SHV. ${ }^{27}$ However, numerous publications have demonstrated significant differences between labeled valve size and the actual dimensions of the valve-related sizer barrel, causing confusion in the surgical community. ${ }^{3,28-30}$

During labeling, the manufacturer determines which valve is recommended for a measured tissue annulus, which is reflected in the labeled valve size. However, clinical sizing can vary depending on the extent of annular debridement or surgeon aggressiveness when entering the sizer to the annulus. These variabilities make it challenging for manufacturers to determine which valve to recommend

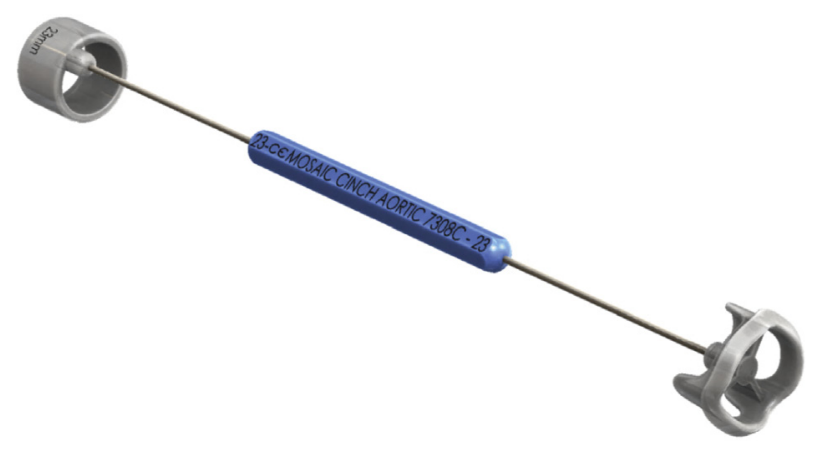

FIGURE 4. Typical 2-ended valve sizer. 
for implanting into a specific tissue annulus diameter (ie, to determine the labeled valve size). Although the actual tissue annulus diameter is easily determined using a Hegar dilator or a similar circular sizing tool, these inconsistencies and challenges mean that optimal sizing is currently best performed using the set of sizers provided by the manufacturer with the valve selected for implantation.

\section{HEMODYNAMIC PERFORMANCE OF SURGICAL PROSTHETIC HEART VALVES \\ In Vitro Hydrodynamic Performance Testing}

In vitro hydrodynamic testing is intended to assess the ability of an SHV to enable forward flow and prevent reverse flow and is required for device approval. Although steady flow testers allow manufacturers to measure forward flow and reverse flow (leakage) across the SHV under controlled conditions, the testing environment is very different from physiological conditions. "ISO 5840:2015" provides guidance for in vitro hydrodynamic performance testing and defines flow hydrodynamic acceptance criteria for pulsatile testing based on valve size and implant position. ${ }^{2}$

Pulsatile testing. Pulsatile testing enables SHV performance to be assessed under physiological flow and pressure conditions that are similar to those in which it is intended to function. Pulsatile testing enables measurement of flow and pressure drop (pressure gradient), calculation of the in vitro effective orifice area (EOA) and total regurgitant volume and fraction. In vitro EOA is derived from the mean pressure difference and forward flow measured across the open valve, while regurgitant fraction is the volume of fluid that flows retrograde through the test valve as a percentage of forward flow. These parameters are defined in "ISO 5840:2015." "2 In vitro EOA is calculated using the following equation:

$$
\text { in vitro } \mathrm{EOA}=\frac{q_{V} \mathrm{RMS}}{51.6 \times \sqrt{\frac{\Delta p}{\rho}}},
$$

where EOA is measured in $\mathrm{cm}^{2}, q_{V \text { RMS }}$ is the root mean square of forward flow ( $\mathrm{mL} / \mathrm{s}), \Delta p$ is the mean pressure difference $(\mathrm{mm} \mathrm{Hg})$, and $\rho$ is the test fluid density $\left(\mathrm{g} / \mathrm{cm}^{3}\right)$.

Pulse duplicator. Pulsatile testing is performed in a test apparatus commonly known as a "pulse duplicator." "ISO 5840:2015" provides specifications for pulsatile testing to reduce variability in testing and reporting methods between testing centres. These include specifications for the test apparatus (pulse duplicator), measurement equipment accuracy and test procedures. ${ }^{2}$ However, pulse duplicators are not perfect substitutes for human anatomy and the physiological conditions in which the SHV is intended to be used. Currently used pulse duplicators vary between test centers and range from simple to sophisticated systems with different degrees of mimicking of the human anatomy. These subtle differences in test environments have a profound effect on the results of pulsatile testing. An interlaboratory round-robin study of SHV in vitro pulsatile testing demonstrated considerable differences in results of hydrodynamic performance measures in different test centers evaluating the same reference valves, using a common ISO-derived protocol. In this study, measures of both forward (EOA) and backward flow (regurgitant fraction) were found to be subject to this effect. ${ }^{31}$ Results of EOA and regurgitant fraction measurements in the participating 6 centers are displayed on Figure 5, for a 25-mm bileaflet mechanical (St. Jude Medical, St. Paul, Minn) and for a 25-mm tissue reference valve (Edwards Lifesciences, Irvine, Calif). This variation in in vitro hemodynamic performance measurements mandates improved standardization of investigational protocols to increase the reproducibility of test results across different centres.

\section{In Vivo Hemodynamic Performance Testing}

The hemodynamic performance of most SHVs is inferior to that of native healthy valves. Hence, the majority of normally functioning SHVs cause some degree of obstruction to blood flow, depending on the model and size of the SHV as well as the patient's cardiac function. Furthermore, several models of SHVs harbor some degree of "physiological" transprosthetic regurgitation, which may be considered as part of washing the valve. Doppler echocardiography is the primary imaging modality used to assess SHV hemodynamic function in vivo, ${ }^{32,33}$ although cardiac catheterization may also be used.

\section{Assessment of Forward Flow Hemodynamics}

Transprosthetic velocity and pressure gradients. Transprosthetic gradients $(\Delta P)$ are measured using Doppler echocardiography and the simplified Bernoulli formula:

$$
\Delta P=4 \times V_{\mathrm{PrV}^{2}}
$$

where $V_{\operatorname{PrV}}$ is the maximal transprosthetic velocity obtained using continuous-wave Doppler echocardiography.

The peak velocity across the prosthesis is to some extent related to valve size, with smaller SHVs having higher velocities. However, in the case of normally functioning aortic SHVs, $V_{\mathrm{PrV}}$ is low, and in high cardiac output or when the left ventricular outflow tract (LVOT) is narrow, the velocity in the LVOT may not be negligible. In these cases, the pressure gradient is more accurately estimated by integrating the velocity proximal to the prosthesis in the following Bernoulli equation:

$$
\Delta P=4 \times\left(V_{\mathrm{PrV}^{2}}-V_{\mathrm{LVOT}^{2}}\right)
$$

Overestimation of the gradients may occur in the presence of significant pressure recovery in any SHV, or in cases of localized high velocities in mechanical SHVs, as discussed later in this section. 


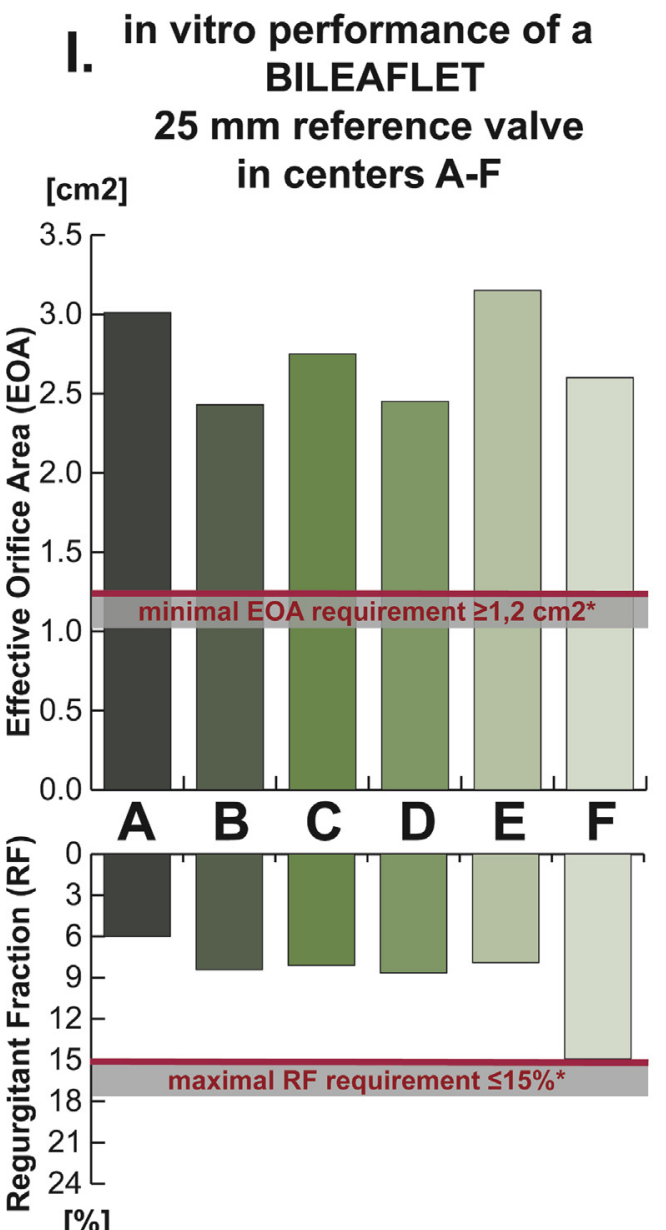

[\%]

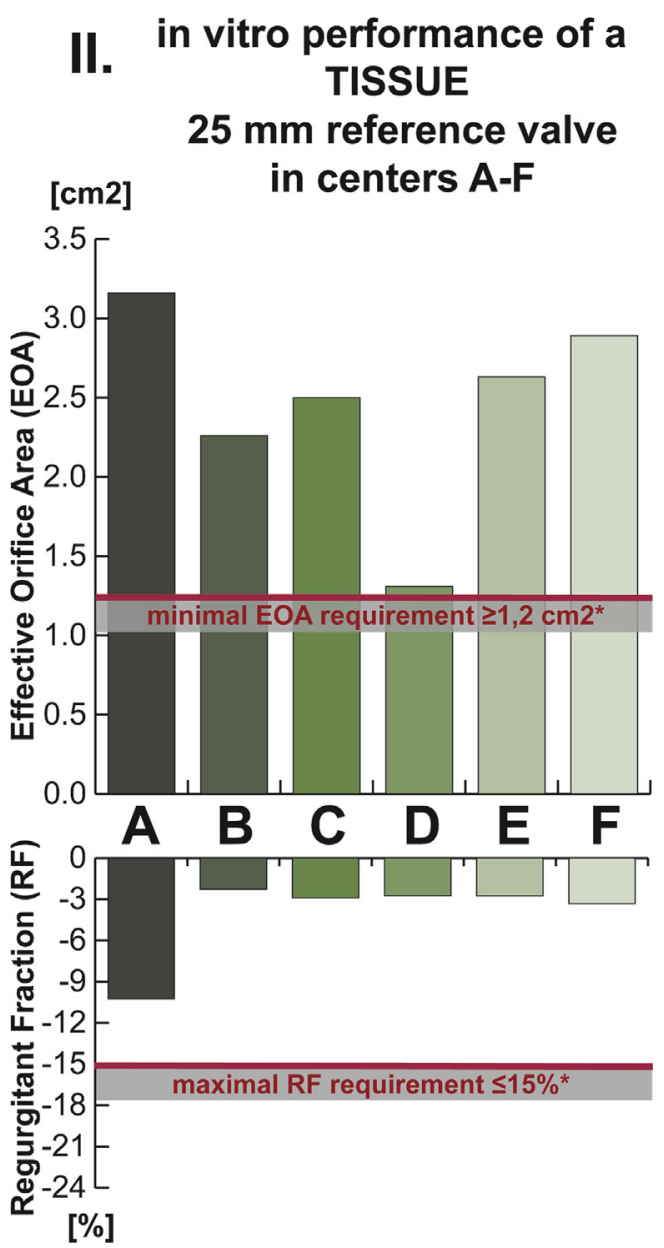

FIGURE 5. In vitro round-robin testing results. (I) EOA and regurgitant fraction results of a 25-mm bileaflet mechanical reference valve (St. Jude Medical, St. Paul, Minn), determined by in vitro pulsatile testing in 6 different centres [(A-F) coded from light to dark shades of green]. (II) EOA and regurgitant fraction results of a $25-\mathrm{mm}$ tissue reference valve (Edwards Lifesciences, Irvine, Calif), determined by in vitro pulsatile testing in 6 different centres [ $(A-F)$ coded from light to dark shades of green]. * Minimum performance requirements, as defined in the International Organization for Standardization 5840:2005 standard. Data from J Heart Valve Dis 2017;26:72-80, by Retta et al. Reproduced by permission. EOA, Effective orifice area; $R F$, regurgitant fraction.

Valve geometric and effective orifice areas. The geometric orifice area (GOA) of the SHV is the area between the free edges of the open leaflets of a bioprosthetic valve, or the area created by the open spaces between the valve ring and leaflet(s) for a mechanical SHV. The GOA represents the area theoretically available for flow. Importantly, GOA should not be mistaken for the internal orifice area, which is the area calculated from the ID of the SHV stent/ housing. Typically, the GOA is smaller than the internal orifice area, because internal orifice area does not account for the space occupied by the leaflets in the SHV orifice (Figure 6).

Similarly, the in vivo EOA is smaller than the GOA, as it corresponds to the smallest area of the flow jet passing through the prosthesis as it exits the valve (Figure 6). The flow contraction coefficient (ie, the ratio EOA/GOA) varies from 0.70 to 0.90 . From a pathophysiological perspective, transvalvular pressure gradients are more closely related to EOA than to GOA.

The in vivo EOA is less flow-dependent than the transprosthetic velocity or gradient, and is thus often a better metric of intrinsic valve hemodynamic performance. For both aortic and mitral SHVs, the EOA is calculated using the continuity equation method incorporating the stroke volume measured in the LVOT using pulsed-wave Doppler echocardiography:

$$
\text { in vivo } \mathrm{EOA}=\frac{\mathrm{CSA}_{\mathrm{LVOT}} \times \mathrm{VTI}_{\mathrm{LVOT}}}{\mathrm{VTI}_{\mathrm{PrV}}},
$$

where CSA $\mathrm{LVOT}_{\text {in }}$ is the cross-sectional area of the LVOT, calculated from the ID of the LVOT, measured just proximal to the apical border of the SHV stent/sewing ring; $\mathrm{VTI}_{\mathrm{LVOT}}$ 


\section{Bioprosthetic Mechanical}
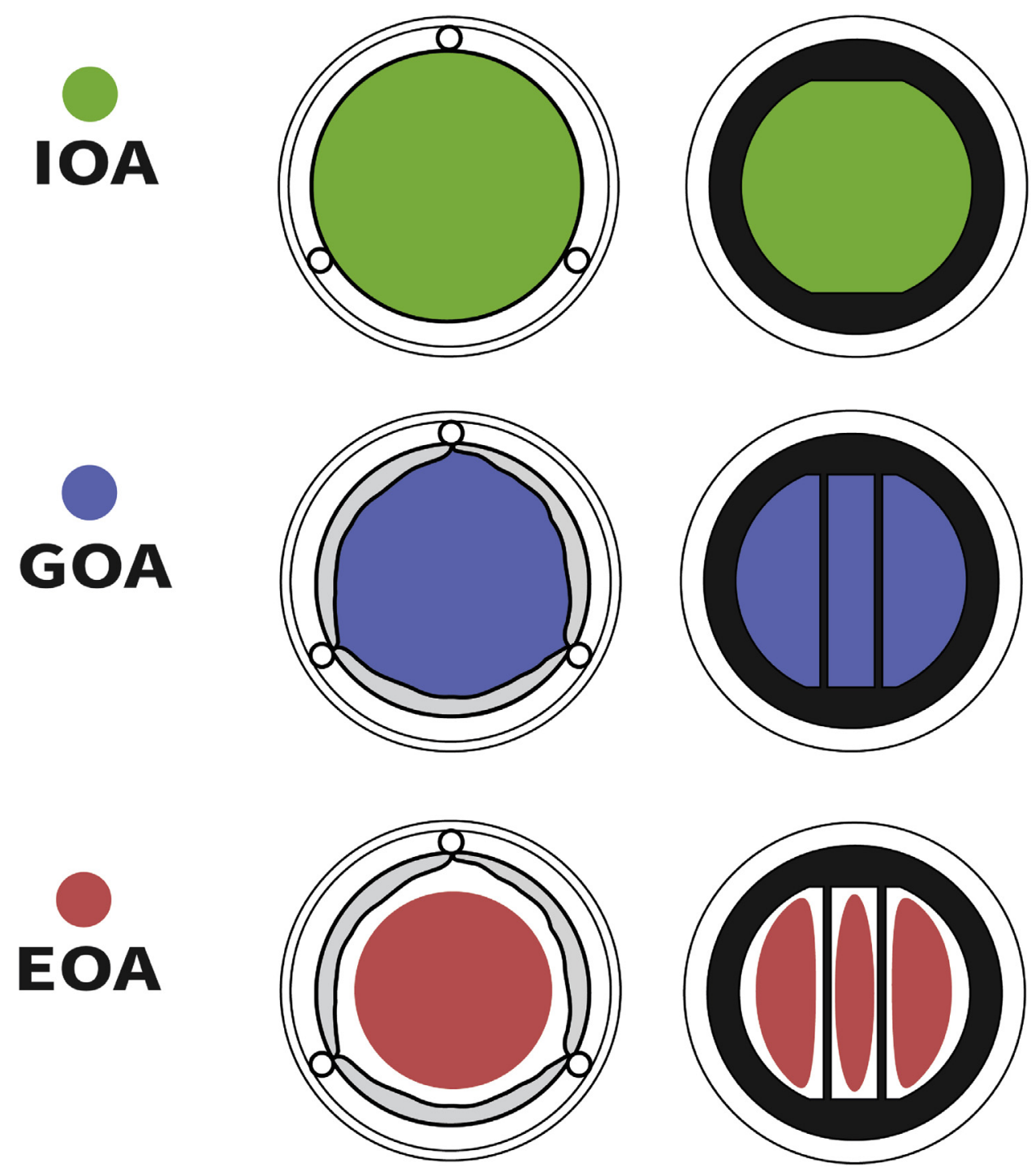

FIGURE 6. IOA, GOA, and EOA in bioprosthetic and mechanical valves. EOA, Effective orifice area; GOA, geometric orifice area; IOA, internal orifice area.

is the velocity-time integral (VTI) of blood flow in the LVOT measured using pulsed-wave Doppler echocardiography in the LVOT just proximal to the apical border of the SHV stent/sewing ring; and $\mathrm{VTI}_{\mathrm{PrV}}$ is the VTI through the SHV obtained using continuous-wave Doppler echocardiography. It should be noted that each of these parameters $\left(\mathrm{CSA}_{\mathrm{LVOT}}, \mathrm{VTI}_{\mathrm{LVOT}}\right.$, and $\left.\mathrm{VTI}_{\mathrm{PrV}}\right)$ may be subject to certain measurement errors. ${ }^{32,34}$ In particular, the $\mathrm{CSA}_{\mathrm{LVOT}}$ might be underestimated by transthoracic echocardiography because the cross-section of the LVOT is often elliptic and transthoracic echocardiography measures the smaller diameter of the ellipse. Some studies therefore suggested to use 3D imaging modalities (eg, 3D transoesophageal echocardiography or multidetector computed tomography) to measure CSA ${ }_{\mathrm{LVOT}}$ for EOA calculations. ${ }^{35}$ However, this approach did not demonstrate any incremental prognostic value compared to standard EOA calculations based on transthoracic echocardiography measurements. ${ }^{36,37}$

The normal reference values of EOA depend on the SHV model and size. Therefore, to confirm that an SHV has a normal function, the in vivo-obtained EOA should be compared with the normal in vivo EOA value reported for the same model and size of SHV. ${ }^{32}$ Normal SHV function is defined as an in vivo EOA that is within \pm 1 standard deviation (SD) of normal value for the corresponding model and size of SHV. ${ }^{32,38}$ A difference of more than 2 SDs 
between the normal reference value and the in vivo EOA measured in the patient suggests prosthetic valve stenosis. ${ }^{32}$ Doppler velocity index (or dimensionless ratio). For aortic SHVs, the Doppler velocity index (DVI) is calculated as the ratio of the VTI in the LVOT to the transprosthetic flow VTI:

$$
\mathrm{DVI}=\frac{\mathrm{VTI}_{\mathrm{LVOT}}}{\mathrm{VTI}_{\mathrm{PrV}}}
$$

For mitral SHVs, the DVI is calculated as the ratio of the transprosthetic flow VTI to the LVOT VTI:

$$
\mathrm{DVI}=\frac{\mathrm{VTI}_{\mathrm{PrV}}}{\mathrm{VTI}_{\mathrm{LVOT}}}
$$

The DVI is $\geq 0.30$ for a normally functioning aortic SHV and $<2.2$ for a normally functioning mitral SHV. The DVI has the advantage over the EOA of being less subject to measurement variability and less dependent on SHV size.

Pressure recovery and localized high gradient. In patients with an aortic SHV and small aorta relative to the valve EOA, a substantial proportion of the pressure generated by the left ventricle might initially be lost between the LVOT and the vena contracta of the SHV flow, but may be recovered downstream to the vena contracta (Figure 7). This phenomenon is called pressure recovery and may occur with both native and prosthetic valves.

Given that Doppler echocardiography measures the highest $V_{\operatorname{PrV}}$ and thus transprosthetic gradient at the level of the vena contracta, and that cardiac catheterization measures the aortic pressure and gradient downstream of the vena contracta (and thus downstream of the pressure recovery phenomenon), Doppler echocardiography may yield higher values of gradients and smaller values of EOA compared with catheterization (Figure 7). Failure to take "pressure recovery" into account may lead to overestimation of the transprosthetic gradient and underestimation of the EOA using Doppler echocardiography, especially in patients with an ascending aortic diameter $<30 \mathrm{~mm}$. It is possible to correct the EOA for the extent of pressure recovery by calculating the energy loss coefficient (ELC). The ELC adjusts the Doppler EOA for the size of the ascending aorta in order to account for the extent of pressure recovery:

$$
\mathrm{ELC}=\frac{\mathrm{EOA} \times \mathrm{AA}}{\mathrm{AA}-\mathrm{EOA}},
$$

where AA is the cross-sectional area of the aorta measured about $1 \mathrm{~cm}$ downstream of the sinotubular junction. ${ }^{39}$ The ELC, in fact, provides an estimate of the EOA measured by catheterization.

In bileaflet mechanical valves, a localized high velocity may be recorded using continuous-wave Doppler echocardiography through the central orifice of the valve, which is often smaller than the 2 lateral orifices. This may yield an overestimation of the transvalvular gradient (by an average of $5 \%-15 \%$ compared with cardiac catheterization) and underestimation of the EOA. ${ }^{40}$

\section{Assessment of Physiological Prosthetic Heart Valve Regurgitation}

All mechanical SHVs have a regurgitant volume (2-10 $\mathrm{mL}$ ) that includes a closing volume (necessary for closing the occluders) and/or a washing/leakage volume (through the components), which contribute to the prevention of blood stasis and thrombus formation. Normal leakage backflow jets are narrow at their origin, often symmetrical, and have a homogeneous color without significant aliasing (Figure 8$)$. Of note, trace $(<1 \mathrm{~mL})$ central leakage may also occur in normally functioning bioprosthetic valves. It is important to separate physiological from pathological prosthesis regurgitation.

The approach for detecting and grading SHV regurgitation is similar to that for native valves and involves color Doppler imaging in multiple views and planes as well as measurement of several Doppler echocardiographical parameters. ${ }^{32,41}$ There are limited data on the application and validation of semi-quantitative and quantitative parameters such as width of the regurgitant jet or of the vena contracta, the effective regurgitant orifice area, and the regurgitant volume and fraction in the context of prosthetic valves. ${ }^{42}$ Given that all parameters of SHV regurgitation have important limitations and may be subject to measurement errors, a comprehensive, multiparametric integrative approach is recommended. $^{32,41}$ Cardiac MRI using phase-contrast sequences may be helpful to quantitate SHV regurgitation. ${ }^{43}$

\section{Prosthesis-Patient Mismatch}

Prosthesis-patient mismatch (PPM) after surgical aortic valve replacement (SAVR) occurs when a patient receives an SHV that has insufficient EOA relative to cardiac output requirements.

After indexing EOA to the body surface area (BSA), PPM after SAVR is considered to be "moderate" if the indexed EOA is $0.66-0.85 \mathrm{~cm}^{2} / \mathrm{m}^{2}$, and "severe" if indexed EOA is $\leq 0.65 \mathrm{~cm}^{2} / \mathrm{m}^{2}{ }^{32}$ In obese patients [body mass in$\operatorname{dex}(\mathrm{BMI}) \geq 30 \mathrm{~kg} / \mathrm{m}^{2}$ ], it is recommended to use lower cut-off values of indexed EOA to define "moderate" and "severe" PPM $\left(0.56-0.70\right.$ and $\leq 0.55 \mathrm{~cm}^{2} / \mathrm{m}^{2}$, respectively). ${ }^{32,44}$ In a meta-analysis of 34 studies on PPM after SAVR, the rates of moderate and severe PPM were $34.2 \%$ and $9.8 \%$, respectively. ${ }^{1}$ Predictors for PPM are female sex, larger BSA, larger BMI, diabetes, hypertension, and renal failure. ${ }^{45}$ Mechanical valves generally have a slightly larger EOA than bioprosthetic valves with the same labeled size, and they are associated with lower PPM rates. ${ }^{46}$ 


\section{Large aorta diameter, minimal pressure recovery}

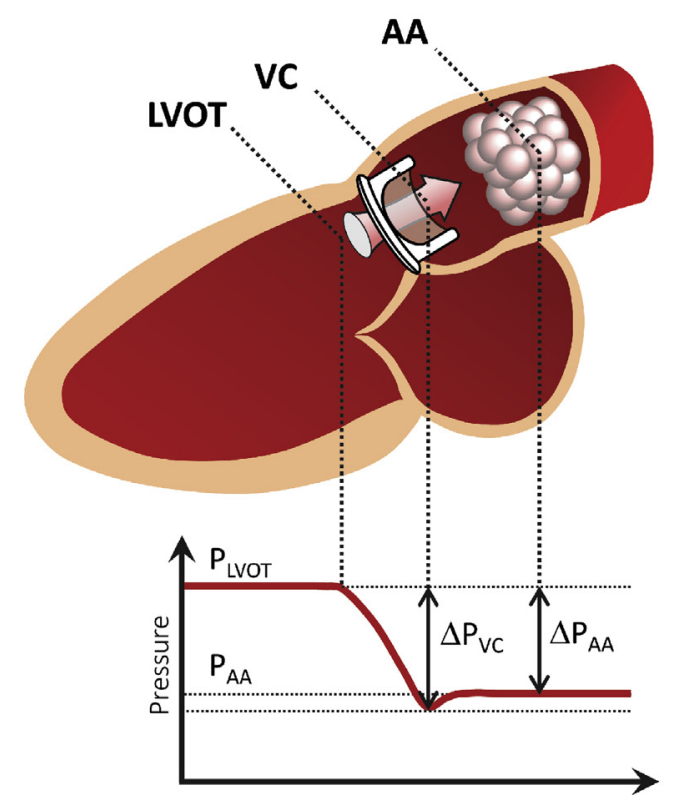

\section{Small aorta diameter, significant pressure recovery}

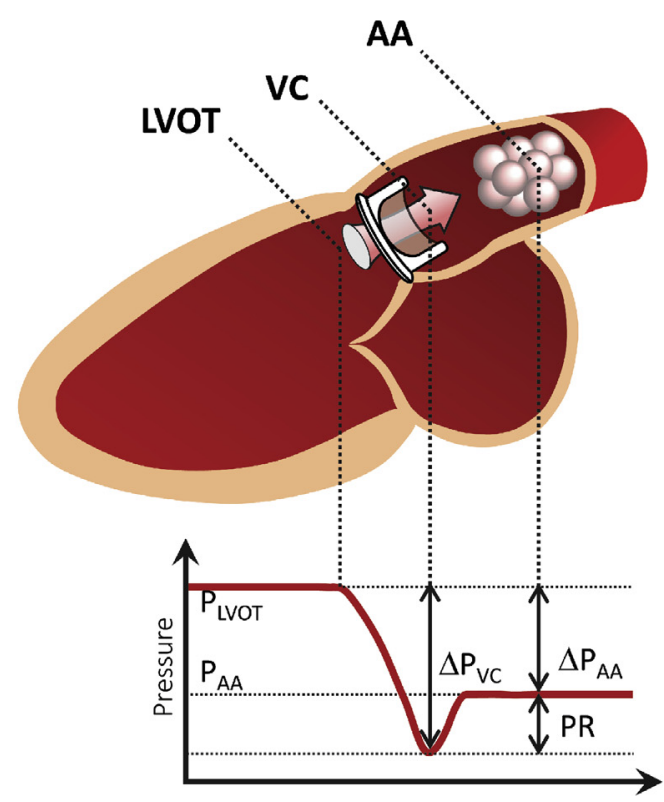

FIGURE 7. Pressure recovery. (I) Large aorta diameter, minimal pressure recovery. Pressure gradients between the LVOT and VC, and between the LVOT and AA are similar. (II) Small aorta diameter, significant pressure recovery. Pressure gradients between the LVOT and VC, and between the LVOT and AA are different. $A A$, Ascending aorta; $L V O T$, left ventricular outflow tract; $P_{A A}$, ascending aortic pressure; $P_{L V O T}$, left ventricular outflow tract pressure; $P R$, pressure recovery; $\Delta P_{A A}$, pressure gradient between the LVOT and the ascending aorta; $\Delta P_{V C}$, pressure gradient between the LVOT and the vena contracta; $V C$, vena contracta.

The presence of PPM results in higher postoperative residual transvalvular gradients, which have been associated with less left ventricular mass regression, worse functional class and quality of life, higher risk of hospitalization due to heart failure, and higher short- and long-term mortality rates after SAVR. ${ }^{1,47}$ Furthermore, studies have suggested that structural valve degeneration is accelerated if PPM is present. ${ }^{48}$ In summary, PPM after SAVR impacts prognosis at various follow-up stages, and prevention of PPM should be a priority, especially in young, active patients and those with left ventricular systolic dysfunction.

A tool for predicting PPM after SAVR is available: multiplying the patient's BSA by 0.85 calculates the minimum EOA value required to prevent PPM, thus allowing surgeons to select an appropriate SHV to obtain the desired EOA. ${ }^{49}$ In cases where the aortic annulus is too small to fit an acceptable valve, aortic annulus or root enlargement may be considered to facilitate implantation of a larger prosthesis. Reliable data on EOA are critical to the success of this strategy.

Valve manufacturers have provided valve-specific charts that can be used intraoperatively to predict PPM. Ideally, comparing these charts would allow the surgeon to select the optimal valve for the patient to avoid PPM. However, accurate prediction of severe PPM using these charts has been reported to be as low as 59\%. ${ }^{50}$ Moreover, these charts have been severely criticized for lack of uniformity: different cut-offs were used to define PPM; in some instances, in vitro data were used to determine EOA and in vivo echocardiographical studies were occasionally selected to include those with the largest EOA values. Furthermore, even normal reference values of SHV hemodynamic performance reported in the literature are derived mostly from single-center studies without core laboratory evaluation of SHV function. ${ }^{32}$ These issues render effective prevention of PPM challenging.

\section{THROMBOGENICITY OF PROSTHETIC HEART VALVES}

The risk of bleeding and thromboembolic events after SHV implantation depends on the type and anatomical position of the prosthesis, anticoagulation strategy, and patient-related risk factors, such as hematological disorders, arrhythmias, and cardiac chamber dilatation or function. "ISO 5840:2015" defines objective performance criteria for bleeding and thromboembolic events for the clinical evaluation of SHVs. ${ }^{2,5,6}$

North American and European clinical practice guidelines provide recommendations on postprocedural anticoagulation after mechanical and bioprosthetic valve 

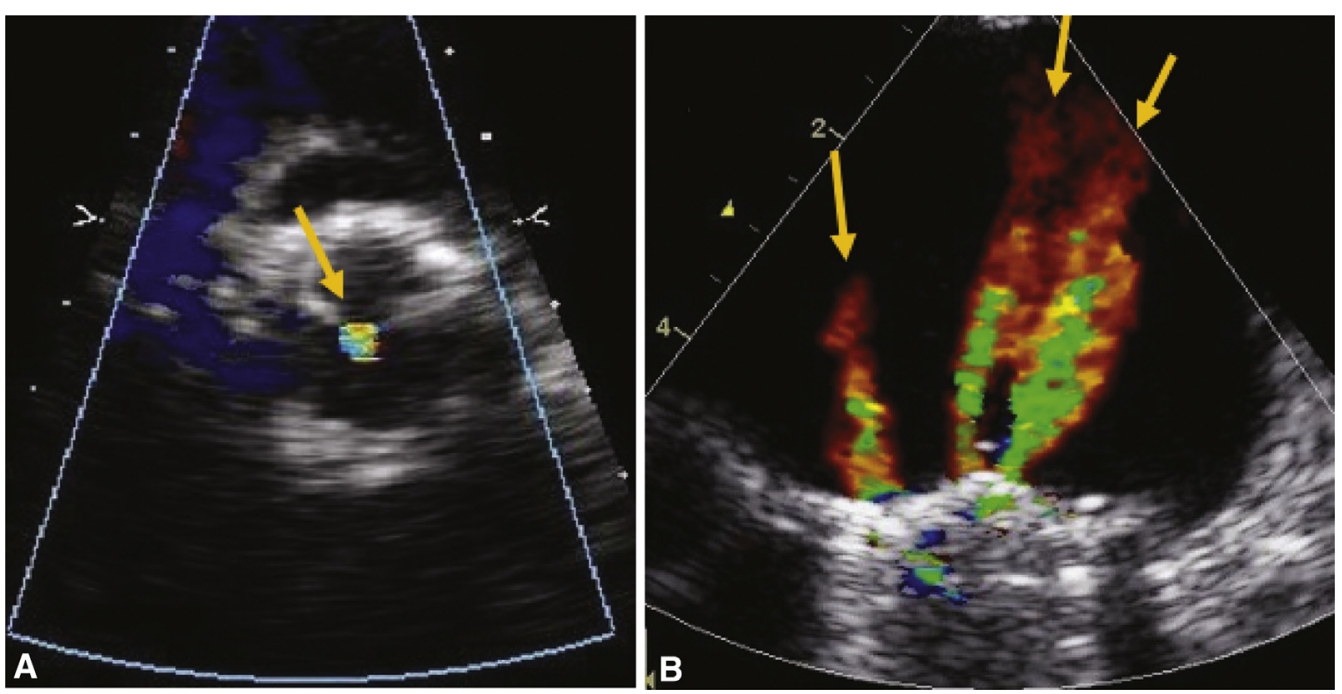

FIGURE 8. Normal regurgitant jet in bioprosthetic and mechanical valves. Normal "physiological regurgitant" jets (orange arrows) in a stented bioprosthetic aortic valve $(A)$ and in a bileaflet mechanical mitral valve $(B)$.

replacement. $^{51,52}$ In contrast to bioprosthetic SHVs, mechanical valves require lifelong anticoagulation with vitamin-K antagonists. Treatment with vitamin-K antagonists carries certain risks and demands rigorous patient compliance. To date, no viable alternative to vitamin-K antagonists in this setting has been identified, ${ }^{53,54}$ but numerous studies have been performed to investigate the safety of a lower international normalized ratio (INR) target in patients with mechanical valves in the aortic position. ${ }^{46,55}$ In the EU, 2 mechanical SHVs have received regulatory approval for reduced anticoagulation, if used in the aortic position in patients with low risk for thromboembolic events ${ }^{54,56}$; this information is often displayed on the device packaging and used in marketing materials. However, there are no comparisons among currently used valves, so it cannot be concluded whether a lower INR is safe in only those 2 valves or also in others. ${ }^{46}$ Indeed, clinical practice guidelines categorize mechanical SHVs on the basis of their thrombogenicity, with most contemporary mechanical valves falling into the "low thrombogenicity" category, ${ }^{51,52}$ and several studies with the use of mechanical valves not specifically approved for lower INR ranges have also shown improved safety and similar efficacy with lower INR ranges. ${ }^{46,55}$

In bioprosthetic valves, the issue of subclinical leaflet thrombosis has been raised recently ${ }^{57,58}$ and clearly deserves further study. It remains unclear whether bioprosthetic valve thrombosis occurs more frequently with some valves compared with others or why the rate is lower in SHVs than in transcatheter valves. ${ }^{58}$ Comparative studies are needed to differentiate thrombotic risk among various valves. These should be carefully evaluated before statements are made on anticoagulation for bioprostheses, which would have possible ramifications for labeling.

\section{DISCUSSION}

Sizing and labeling of SHVs are complex issues that span the domains of clinical practice, engineering, and product manufacturing, and have important regulatory aspects. Currently, many unanswered questions surround intraoperative sizing and labeling of SHVs, making optimal intraoperative SHV selection challenging. These include:

1. nonuniform or incomplete reporting of SHV materials and physical dimensions in the IFU;

2. unclear definition of labeled valve size and inconsistencies between sizer dimensions and labeled valve size;

3. nonuniform marking of SHV support structures;

4. lack of robust information on in vivo hemodynamic performance in the IFU, and no information available regarding hemodynamic performance on package labels;

5. lack of uniform tools backed by solid evidence to prevent PPM; and

6. lack of good-quality, robust clinical data on SHV thrombogenicity.

This situation has persisted for decades and has received many calls for action, but no uniform solution has been achieved to date.

Determining the right amount of information for intraoperative decision-making requires finding a delicate balance. Although currently available parameters on the package labels provide incomplete information regarding the most important characteristics of the SHV, the inclusion 
of redundant or irrelevant information would similarly create confusion in the surgical community.

Complex issues are best prioritized and solved through concentrated efforts from all critical stakeholders. ${ }^{59}$ The EACTS-STS-AATS Valve Labelling article Project has been initiated with this intention. The medical community requires clarity and should work together with valve manufacturers, regulatory bodies, and the ISO group to achieve an optimal solution. This article has summarized the most important characteristics of SHVs and the background of SHV labeling and is intended to pave the way for an EACTS-STS-AATS Expert Consensus Document that will include recommendations on SHV sizing and labeling.

\section{CONCLUSION}

This joint EACTS-STS-AATS Labelling Task Force has identified several issues related to SHV sizing and labeling. These issues should be addressed to ensure that surgeons are provided with sufficient, appropriate, and standardized information required for optimal SHV choice.

\section{Conflict of Interest Statement}

Vinayak Bapat served as a consultant for Edwards Lifesciences, Medtronic and 4Tech Inc.; Filip P.A. Casselman served as a consultant for Edwards Lifesciences and Medtronic; Edward P. Chen served as a consultant for CryoLife and as a proctor for Medtronic; Philippe Pibarot has received research grant support from Edwards Lifesciences and Medtronic for echocardiography core laboratory analyses in transcatheter heart valves; Giordano Tasca reports speaker fees from St. Jude Medical; Marco Stijnen is an employee of LifeTec Group; Ruggero De Paulis served as consultant for Edwards Lifesciences and Medtronic. All other authors declared no conflict of interest.

The authors would like to acknowledge the help of Rianne Kalkman (EACTS Office) in coordinating the Task Force activities.

\section{References}

1. Head SJ, Mokhles MM, Osnabrugge RL, Pibarot P, Mack MJ, Takkenberg JJ, et al. The impact of prosthesis-patient mismatch on long-term survival after aortic valve replacement: a systematic review and meta-analysis of 34 observational studies comprising 27186 patients with 133141 patient-years. Eur Heart J. 2012;33:1518-29.

2. ISO. International Standard, ISO 5840:2015. Cardiovascular Implants—Cardiac Valve Prostheses. International Organization for Standardization (ISO); 2015. Available at: http://www.iso.org. Accessed April 3, 2018.

3. Doenst T, Amorim PA, Al-Alam N, Lehmann S, Mukherjee C, Faerber G. Where is the common sense in aortic valve replacement? A review of hemodynamics and sizing of stented tissue valves. J Thorac Cardiovasc Surg. 2011;142:1180-7.

4. ISO. ISO-International Organization for Standardization. 2018. Available at: https://www.iso.org/home.html. Accessed March 14, 2018.

5. Wu Y, Butchart EG, Borer JS, Yoganathan A, Grunkemeier GL. Clinical evaluation of new heart valve prostheses: update of objective performance criteria. Ann Thorac Surg. 2014;98:1865-74.
6. Head SJ, Mylotte D, Mack MJ, Piazza N, van Mieghem NM, Leon MB, et al. Considerations and recommendations for the introduction of objective performance criteria for transcatheter aortic heart valve device approval. Circulation. 2016;133:2086-93.

7. The Council of the European Communities, Council Directive 93/42/EEC. Available at: http://eur-lex.europa.eu/LexUriServ/LexUriServ.do?uri=CONSLEG: 1993L0042:20071011:en:PDF. Accessed April 3, 2018.

8. The European Parliament and the Council of the European Union, Regulation (EU) 2017/745. Available at: http://eur-lex.europa.eu/legal-content/ENG/TXT/ PDF/?uri= CELEX:32017R0745\&from =EN. Accessed April 3, 2018.

9. International Organization for Standardization (ISO), European Committee for Standardization (CEN). Agreement on Technical Co-operation between ISO and CEN (Vienna Agreement). 2001. Available at: https://boss.cen.eu/ref/ Vienna_Agreement.pdf. Accessed April 3, 2018.

10. U.S. Food and Drug Administration. FDA Organization. U.S. Department of Health and Human Services; 2018. Available at: https://www.fda.gov/ AboutFDA/CentersOffices/default.htm. Accessed April 3, 2018.

11. U.S. Food and Drug Administration. Premarket Approval (PMA). U.S. Department of Health and Human Services; 2018. Available at: https://www.fda.gov/ MedicalDevices/DeviceRegulationandGuidance/HowtoMarketYourDevice/ PremarketSubmissions/PremarketApprovalPMA/ucm2007514.htm\#data. Accessed April 3, 2018

12. U.S. Food and Drug Administration. Recognition and Use of Consensus Standards, Guidance for Industry and FDA Staff. U.S. Food and Drug Administration; 2007. Available at: https://www.fda.gov/downloads/medicaldevices/device regulationandguidance/guidancedocuments/ucm077295.pdf. Accessed April 3, 2018.

13. Mohammadi H, Mequanint K. Prosthetic aortic heart valves: modeling and design. Med Eng Phys. 2011;33:131-47.

14. Konakci KZ, Bohle B, Blumer R, Hoetzenecker W, Roth G, Moser B, et al. Alpha-Gal on bioprostheses: xenograft immune response in cardiac surgery. Eur J Clin Invest. 2005;35:17-23.

15. Flameng W, Rega F, Vercalsteren M, Herijgers P, Meuris B. Antimineralization treatment and patient-prosthesis mismatch are major determinants of the onset and incidence of structural valve degeneration in bioprosthetic heart valves. J Thorac Cardiovasc Surg. 2014;147:1219-24.

16. Scherman J, Bezuidenhout D, Ofoegbu C, Williams DF, Zilla P. TAVI for low to middle income countries. Eur Heart J. 2017;38:1182-4.

17. Bezuidenhout D, Williams DF, Zilla P. Polymeric heart valves for surgical implantation, catheter-based technologies and heart assist devices. Biomaterials. 2015;36:6-25.

18. Glaser N, Jackson V, Franco-Cereceda A, Sartipy U. Survival after aortic valve replacement with bovine or porcine valve prostheses: a systematic review and meta-analysis. Thorac Cardiovasc Surg. 2018; https://doi.org/10.1055/s-00381649513 [Epub ahead of print].

19. Hickey GL, Bridgewater B, Grant SW, Deanfield J, Parkinson J, Bryan AJ, et al. National registry data and record linkage to inform postmarket surveillance of prosthetic aortic valve models over 15 Years. JAMA Intern Med. 2017;177: 79-86.

20. Allen KB, Chhatriwalla AK, Cohen DJ, Saxon JT, Aggarwal S, Hart A, et al. Bioprosthetic valve fracture to facilitate transcatheter valve-in-valve implantation. Ann Thorac Surg. 2017;104:1501-8.

21. Bapat V, Mydin I, Chadalavada S, Tehrani H, Attia R, Thomas M. A guide to fluoroscopic identification and design of bioprosthetic valves: a reference for valve-in-valve procedure. Catheter Cardiovasc Interv. 2013;81:853-61.

22. Bapat VN, Attia R, Thomas M. Effect of valve design on the stent internal diameter of a bioprosthetic valve: a concept of true internal diameter and its implications for the valve-in-valve procedure. JACC Cardiovasc Interv. 2014; 7:115-27.

23. Cevasco M, Mick SL, Kwon M, Lee LS, Chen EP, Chen FY. True external diameter better predicts hemodynamic performance of bioprosthetic aortic valves than the manufacturers' stated size. J Heart Valve Dis. 2013;22: 377-82.

24. Ruzicka DJ, Hettich I, Hutter A, Bleiziffer S, Badiu CC, Bauernschmitt R, et al. The complete supraannular concept: in vivo hemodynamics of bovine and porcine aortic bioprostheses. Circulation. 2009;120:S139-45.

25. Tabata M, Shibayama K, Watanabe H, Sato Y, Fukui T, Takanashi S. Simple interrupted suturing increases valve performance after aortic valve replacement with a small supra-annular bioprosthesis. J Thorac Cardiovasc Surg. 2014;147: 321-5.

26. Cameron D. Little things matter. J Thorac Cardiovasc Surg. 2015;149:918-9. 
27. Christakis GT, Buth KJ, Goldman BS, Fremes SE, Rao V, Cohen G, et al. Inaccurate and misleading valve sizing: a proposed standard for valve size nomenclature. Ann Thorac Surg. 1998;66:1198-203.

28. Ruzicka DJ, Eichinger WB, Hettich IM, Bleiziffer S, Bauernschmitt R, Lange R. Hemodynamic performance of the new St. Jude Medical Epic Supra porcine bioprosthesis in comparison to the Medtronic Mosaic on the basis of patient annulus diameter. J Heart Valve Dis. 2008;17:426-33; discussion 34 .

29. Walther T, Falk V, Weigl C, Diegeler A, Rauch T, Autschbach R, et al. Discrepancy of sizers for conventional and stentless aortic valve implants. $J$ Heart Valve Dis. 1997;6:145-8.

30. Bartels C, Leyh RG, Matthias Bechtel JF, Joubert-Hubner E, Sievers HH. Discrepancies between sizer and valve dimensions: implications for small aortic root. Ann Thorac Surg. 1998;65:1631-3.

31. Retta SM, Kepner J, Marquez S, Herman BA, S Shu MC, Grossman LW. In-vitro pulsatile flow measurement in prosthetic heart valves: an inter-laboratory comparison. J Heart Valve Dis. 2017;26:72-80.

32. Lancellotti P, Pibarot P, Chambers J, Edvardsen T, Delgado V, Dulgheru R, et al. Recommendations for the imaging assessment of prosthetic heart valves: a report from the European Association of Cardiovascular Imaging endorsed by the Chinese Society of Echocardiography, the Inter-American Society of Echocardiography and the Brazilian Department of Cardiovascular Imaging. Eur Heart J Cardiovasc Imaging. 2016;17:589-90.

33. Zoghbi WA, Chambers JB, Dumesnil JG, Foster E, Gottdiener JS, Grayburn PA, et al. Recommendations for evaluation of prosthetic valves with echocardiography and Doppler ultrasound: a report from the American Society of Echocardiography's Guidelines and Standards Committee and the task force on prosthetic valves, developed in conjunction with the American College of Cardiology Cardiovascular Imaging Committee, Cardiac Imaging Committee of the American Heart Association, the European Association of Echocardiography, a registered branch of the European Society of Cardiology, the Japanese Society of Echocardiography and the Canadian Society of Echocardiography, endorsed by the American College of Cardiology Foundation, American Heart Association, European Association of Echocardiography, a registered branch of the European Society of Cardiology, the Japanese Society of Echocardiography, and Canadian Society of Echocardiography. J Am Soc Echocardiogr. 2009;22: 975-1014.

34. Gaspar T, Adawi S, Sachner R, Asmer I, Ganaeem M, Rubinshtein R, et al. Three-dimensional imaging of the left ventricular outflow tract: impact on aortic valve area estimation by the continuity equation. J Am Soc Echocardiogr. 2012; 25:749-57.

35. Kamperidis V, van Rosendael PJ, Katsanos S, van der Kley F, Regeer M, Al Amri I, et al. Low gradient severe aortic stenosis with preserved ejection fraction: reclassification of severity by fusion of Doppler and computed tomographic data. Eur Heart J. 2015;36:2087-96.

36. Mooney J, Sellers SL, Blanke P, Pibarot P, Hahn RT, Dvir D, et al. CT-defined prosthesis-patient mismatch downgrades frequency and severity, and demonstrates no association with adverse outcomes after transcatheter aortic valve replacement. JACC Cardiovasc Interv. 2017;10:1578-87.

37. Clavel MA, Malouf J, Messika-Zeitoun D, Araoz PA, Michelena HI, EnriquezSarano M. Aortic valve area calculation in aortic stenosis by CT and Doppler echocardiography. JACC Cardiovasc Imaging. 2015;8:248-57.

38. Hahn RT, Leipsic J, Douglas PS, Jaber WA, Weissman NJ, Pibarot P, et al. Comprehensive echocardiographic assessment of normal transcatheter valve function. JACC Cardiovasc Imaging. 2019;12:25-34.

39. Pibarot P, Garcia D, Dumesnil JG. Energy loss index in aortic stenosis: from fluid mechanics concept to clinical application. Circulation. 2013;127:1101-4.

40. Evin M, Pibarot P, Guivier-Curien C, Tanne D, Kadem L, Rieu R. Localized transvalvular pressure gradients in mitral bileaflet mechanical heart valves and impact on gradient overestimation by Doppler. J Am Soc Echocardiogr. 2013; 26:791-800.

41. Pibarot P, Hahn RT, Weissman NJ, Monaghan MJ. Assessment of paravalvular regurgitation following TAVR: a proposal of unifying grading scheme. JACC Cardiovasc Imaging. 2015;8:340-60.

42. Fattouch K, Lancellotti P, Vannan MA, Speziale G, eds. Advances in Treatments for Aortic Valve and Root Diseases. 1st edn. Springer International Publishing; 2018. Available at: https://doi.org/10.1007/978-3-319-66483-5.

43. Ribeiro HB, Orwat S, Hayek SS, Larose É, Babaliaros V, Dahou A, et al. Cardiovascular magnetic resonance to evaluate aortic regurgitation after transcatheter aortic valve replacement. J Am Coll Cardiol. 2016;68:577-85.
44. Mohty D, Dumesnil JG, Echahidi N, Mathieu P, Dagenais F, Voisine P, et al Impact of prosthesis-patient mismatch on long-term survival after aortic valve replacement: influence of age, obesity, and left ventricular dysfunction. J Am Coll Cardiol. 2009;53:39-47.

45. Dayan V, Vignolo G, Soca G, Paganini JJ, Brusich D, Pibarot P. Predictors and outcomes of prosthesis-patient mismatch after aortic valve replacement. JACC Cardiovasc Imaging. 2016;9:924-33.

46. Head SJ, Celik M, Kappetein AP. Mechanical versus bioprosthetic aortic valve replacement. Eur Heart J. 2017;38:2183-91.

47. Fallon JM, DeSimone JP, Brennan JM, O'Brien S, Thibault DP, DiScipio AW et al. The incidence and consequence of prosthesis-patient mismatch after surgical aortic valve replacement. Ann Thorac Surg. 2018;106:14-22.

48. Johnston DR, Soltesz EG, Vakil N, Rajeswaran J, Roselli EE, Sabik JF III, et al Long-term durability of bioprosthetic aortic valves: implications from 12,569 implants. Ann Thorac Surg. 2015;99:1239-47.

49. Pibarot P, Dumesnil JG. Prosthesis-patient mismatch: definition, clinical impact and prevention. Heart. 2006;92:1022-9.

50. Bleiziffer S, Eichinger WB, Hettich I, Guenzinger R, Ruzicka D, Bauernschmitt R, et al. Prediction of valve prosthesis-patient mismatch prior to aortic valve replacement: which is the best method? Heart. 2007;93:615-20.

51. Falk V, Baumgartner H, Bax JJ, De Bonis M, Hamm C, Holm PJ, et al. 2017 ESC EACTS guidelines for the management of valvular heart disease. Eur J Cardiothorac Surg. 2017;52:616-64.

52. Nishimura RA, Otto CM, Bonow RO, Carabello BA, Erwin JP III, Fleisher LA, et al. 2017 AHA/ACC focused update of the 2014 AHA/ACC guideline for the management of patients with valvular heart disease: a report of the American College of Cardiology/American Heart Association task force on clinical practice guidelines. J Am Coll Cardiol. 2017;70:252-89.

53. Eikelboom JW, Connolly SJ, Brueckmann M, Granger CB, Kappetein AP Mack MJ, et al. Dabigatran versus warfarin in patients with mechanical heart valves. N Engl J Med. 2013;369:1206-14.

54. Puskas JD, Gerdisch M, Nichols D, Fermin L, Rhenman B, Kapoor D, et al. Anticoagulation and antiplatelet strategies after On-X mechanical aortic valve replacement. J Am Coll Cardiol. 2018;71:2717-26.

55. Koertke H, Zittermann A, Wagner O, Secer S, Sciangula A, Saggau W, et al. Telemedicine-guided, very low-dose international normalized ratio selfcontrol in patients with mechanical heart valve implants. Eur Heart J. 2015;36:1297-305.

56. Torella M, Aquila I, Chiodini P, Amarelli C, Romano G, Della Ratta EE, et al Low-dose anticoagulation after isolated mechanical aortic valve replacemen with Liva Nova Bicarbon prosthesis: a post hoc analysis of LOWERING-IT Trial. Sci Rep. 2018;8:8405.

57. Makkar RR, Fontana G, Jilaihawi H, Chakravarty T, Kofoed KF, De Backer O, et al. Possible subclinical leaflet thrombosis in bioprosthetic aortic valves. N Engl J Med. 2015;373:2015-24.

58. Chakravarty T, Sondergaard L, Friedman J, De Backer O, Berman D, Kofoed KF, et al. Subclinical leaflet thrombosis in surgical and transcatheter bioprosthetic aortic valves: an observational study. Lancet. 2017;389:2383-92.

59. Kappetein AP, Head SJ, Généreux P, Piazza N, van Mieghem NM Blackstone EH, et al. Updated standardized endpoint definitions for transcatheter aortic valve implantation: the Valve Academic Research Consortium-2 consensus document. Eur J Cardiothorac Surg. 2012;42:S45-60.

Key Words: aortic valve replacement, mitral valve replacement, prosthetic heart valve, surgical prosthetic heart valve (SHV), International Organization for Standardization (ISO), International standard, labeling, sizing, device approval, regulation, valve performance, prosthesis-patient mismatch (PPM), objective performance criteria (OPC)

\section{APPENDIX. TASK FORCE MEMBERS \\ Cardiac Surgeons}

Ruggero De Paulis, European Hospital, Rome, Italy—Task Force chairman

Pavan Atluri, University of Pennsylvania, Philadelphia, $\mathrm{Pa}$, USA 
Vinayak Bapat, New York-Presbyterian/Columbia University Medical Center, New York, NY, USA

Duke E. Cameron, Massachusetts General Hospital, Boston, Mass, USA

Filip P.A. Casselman, OLV Clinic, Aalst, Belgium

Edward P. Chen, Emory University School of Medicine, Atlanta, Ga, USA

Gry Dahle, Oslo University Hospital, Oslo, Norway

Andras P. Durko, Erasmus University Medical Center, Rotterdam, The Netherlands and Medical and Health Science Centre, University of Debrecen, Debrecen, Hungary

Tjark Ebels, University Medical Center Amsterdam, Amsterdam, The Netherlands

John A. Elefteriades, Yale University School of Medicine, New Haven, Conn, USA

Stuart J. Head, Erasmus University Medical Center, Rotterdam, The Netherlands

A. Pieter Kappetein, Erasmus University Medical Center, Rotterdam, The Netherlands

Richard L. Prager, University of Michigan Hospital, Ann Arbor, Mich, USA

Alan Speir, Inova Cardiac and Thoracic Surgery, Falls Church, Va, USA

Giordano Tasca, Hospital A. Manzoni, Lecco, Italy

Thomas Walther, Wolfgang Goethe University, Frankfurt, Germany

\section{Cardiologists}

Patrizio Lancellotti, University of Liège Hospital, Liège, Belgium

Philippe Pibarot, Laval University, Quebec City, Quebec, Canada

Raphael Rosenhek, Medical University of Vienna, Vienna, Austria

\section{Engineers}

Jurgen de Hart, LifeTec Group, Eindhoven, The Netherlands
Marco Stijnen, LifeTec Group, Eindhoven, The Netherlands

ISO

Ajit Yoganathan, Georgia Institute of Technology/Emory School of Medicine, Atlanta, Ga, USA

US Food and Drug Administration

Nicole Ibrahim

John Laschinger

Changfu $\mathrm{Wu}$

\section{Notified Body}

Giovanni Di Rienzo, TÜV SÜD, Munich, Germany

\section{Competent Authorities}

Alexander McLaren, Medicines and Healthcare products Regulatory Agency, London, UK

Hazel Randall, Medicines and Healthcare products Regulatory Agency, London, UK

\section{Industry Representatives}

Lisa Becker, Abbott, Chicago, Ill, USA

Scott Capps, CryoLife, Kennesaw, Ga, USA

Brian Duncan, LivaNova, London, UK

Chad Green, Abbott, Chicago, Ill, USA

John C. Hay, Medtronic, Minneapolis, Minn, USA

Ornella Ieropoli, LivaNova, London, UK

Ashwini A. Jacob, Edwards Lifesciences, Irvine, Calif, USA

Eric Manasse, Abbott, Chicago, Ill, USA

Salvador Marquez, Edwards Lifesciences, Irvine, Calif, USA

William F. Northrup III, CryoLife Kennesaw, Ga, USA

Tim Ryan, Medtronic, Minneapolis, Minn, USA

Wendel Smith, Edwards Lifesciences, Irvine, Calif, USA 